\title{
CAPítTULO 8
}

\section{O USO DO TERRITÓRIO EM PEQUENAS CIDADES A IMPLANTAÇÃO DA MERCEDES-BENZ EM IRACEMÁPOLIS-SP}

Mauricio Lovadini

\section{A INTERNACIONALIZAÇÃO DA PRODUÇ̃̃O E 0 PROCESSO DE REESTRUTURAÇ̃O PRODUTIVA}

O processo de internacionalização do capital alavancado pela expansão das multinacionais para países periféricos ao longo do século $\mathrm{XX}$, associadas às novas formas de produção, atende à lógica de reprodução do modo de produção capitalista, que tem como escopo a acumulação de riquezas.

Harvey (2016) aponta que "o capital se esforça para produzir uma paisagem geográfica favorável à sua própria reprodução e subsequente evolução". A partir do entendimento da efetivação no espaço-tempo dos modos de desenvolvimento do sistema de produção capitalista, ao longo das suas reestruturações, é possível compreender as evoluções das novas formas de produção.

O fenômeno global de reestruturação econômica promoveu uma flexibilização do processo produtivo, fato que levou as multinacionais a adotarem novas estratégias de produção e comercialização.

As transformações organizacionais foram pautadas pelo avanço intensivo e instantâneo de novas tecnologias, da introdução de um modelo de produção 
enxuto com a perspectiva de redução do custo da mão de obra, a partir da automação industrial e da extinção de tarefas administrativas, com a perspectiva de criar uma rede de integração de todo o processo produtivo, do início da produção ao pós-consumo.

A partir da década de 1970 o desenvolvimento informacional passa a dominar as estruturas do modo de produção capitalista, impulsionado por uma grande revolução tecnológica, que trouxe novas configurações para o sistema produtivo. As corporações se espacializaram por regiões do globo com potenciais produtivos e baixos custos. O processo de globalização se intensificou e o sistema mundo capitalista conectou-se em redes materiais e imateriais.

Dicken (2010, p.27) salienta que "Hoje, vivemos em um mundo em que uma profunda integração, organizada basicamente dentro de e entre redes de produção transacionais geograficamente extensas e complexas, e através de uma diversidade de mecanismos, é cada vez mais o padrão".

Santos (2006) aponta que, graças aos progressos técnicos e às formas atuais de realização da vida econômica, cada vez mais as redes são globais: redes produtivas, de comércio, de transporte e de informação.

O acelerado desenvolvimento tecnológico da Terceira Revolução Industrial ou Revolução Técnico-Científica alterou as estruturas do fordismo e implementou novas formas de organização e racionalização do trabalho, flexibilizando o processo produtivo.

\footnotetext{
O mundo praticamente encolhe, devido à eficácia das telecomunicações e dos transportes, os fios da teia global são computadores, fax etc. - tecnologias criadas pela sociedade para atender as suas próprias necessidades - aproximando os lugares e agilizando as tomadas de decisões. O espaço moderno é fluído, é volátil e comporta muitos fluxos de capitais, informações, conhecimentos, serviços, que cruzam as fronteiras instantaneamente. (MENDES, 1997, p.47-48)
}

Durante o segundo quartel do século $\mathrm{XX}$, diversos países periféricos passam a ter uma participação mais ativa no processo de acumulação ampliada do capital, com a instalação de unidades produtivas de multinacionais. Países com potencial produtivo passaram a desenvolver políticas públicas de estímulo aos investimentos estrangeiros diretos, atuando de forma mais participativa no contexto produtivo mundial. Esse fenômeno ocorreu de forma mais intensa em países da Ásia e da América Latina.

A flexibilização da produção é caracterizada por uma produção enxuta (Lean Production) que fomenta um processo de subcontratação de indústrias, produtoras de insumos, peças e de serviços, de acordo com as especificações 
técnicas e diretrizes estabelecidas pela grande corporação. O significativo aumento da subcontratação gera consequências importantes nas relações interindustriais e nas relações de trabalho.

\section{O USO DO TERRITÓRIO E 0 PROCESSO DE INDUSTRIALIZAC̦ÃO NO BRASIL}

O processo de internacionalização da produção inseriu o Brasil como um país industrializado periférico na divisão internacional do trabalho, essa inserção se deu de forma concentrada no estado de São Paulo.

No que tange à distribuição espacial, o processo de desenvolvimento da indústria no Brasil ocorreu de forma concentrada, fundamentalmente na cidade de São Paulo, tendo em vista que a capital paulista criou todas as condições necessárias, herdadas do ciclo do café, para se tornar um espaço dominado por indústrias como em um palimpsesto do uso do território.

Para Selingardi-Sampaio (2009, p. 21), estabeleceu-se no estado de São Paulo uma densa teia de inter-relações de atividades industriais e processo sócio econômico ao longo do tempo, transformando esse espaço, ao longo do século XX, em um Multicomplexo Territorial Industrial (metropolitano/urbano) Paulista.

A estruturação de uma densa rede de interligações industriais, constituída pelas facilidades de infraestruturas e serviços fixos e móveis, como redes de transportes; de rodovias, aeroportos, proximidade ao porto de Santos; ampla rede bancária, restaurantes e hotéis, criaram as condições para a concentração industrial na cidade de São Paulo e no entorno de sua região metropolitana, fomentando o uso do território.

\footnotetext{
O uso do território pode ser definido pela implantação de infraestruturas, para quais estamos igualmente utilizando a denominação de sistemas de engenharia, mas também pelo dinamismo da economia e da sociedade. São os movimentos da população, a distribuição da agricultura, da indústria e dos serviços, o arcabouço normativo, incluídas a legislação civil, fiscal e financeira, que, justamente com o alcance e a extensão da cidadania, configuram as funções do novo espaço geográfico. (SANTOS; SILVEIRA, 2004, p.21).
}

A partir da década de 1960 houve uma relativa desconcentração das atividades industriais da Região Metropolitana de São Paulo em sentido ao interior do estado e outras regiões do Brasil.

O fenômeno da relativa desconcentração das atividades industriais da região metropolitana de São Paulo foi ocasionado pela saturação da capacidade da metrópole em atender às necessidades de novas demandas industriais, mediante ao estrangulamento de infraestruturas, dificuldades atreladas aos altos encargos 
com impostos municipais; intenso fluxo de trânsito, dificuldade de deslocamento da produção e do trabalhador; elevados índices de poluição; mão de obra mais cara e altamente sindicalizada; diminuição de terrenos grandes e planos, sendo esses alguns fatores de deseconomias de aglomeração, incentivando a expansão das indústrias para o interior, mas com uma distância não superior a $200 \mathrm{~km}$ da metrópole e seu mercado consumidor, interligados pelos nodais de sistemas de transportes e comunicações.

De acordo com Lencioni (2004) a industrialização paulista deve ser entendida considerando a cidade-região.

\begin{abstract}
Quanto ao processo de urbanização vem ocorrendo um crescente desenvolvimento dos espaços metropolizados por todo o território paulista. Além do mais, tudo parece indicar que estamos assistindo a constituição de uma cidade-região que faz parte de uma megalópole em formação que tem como centros as metrópoles de São Paulo e Rio de Janeiro. (LENCIONI, 2004, p 67)
\end{abstract}

Diante das transformações no sistema produtivo, pautados pelas novas tecnologias, conhecimento, pesquisas e capital, as cidades passam a ter um novo papel nesse processo, se adequando às novas estruturas organizacionais produtivas. Mendes (1991) pesquisando a industrialização no estado de São Paulo constatou que muitas indústrias nacionais e estrangeiras, estão sendo implantadas em cidades médias localizadas próximas aos principais eixos de transportes (Rodovias Anhanguera, Bandeirantes e Washington Luiz).

A relativa desconcentração industrial gerou a competição entre lugares para atração de grandes corporações. As ofertas de subsídios oferecidas por estados e cidades, gerou uma "guerra dos lugares".

Santos e Silveira (2004, p.112) apontam que "no período da globalização, a velocidade com que os pedaços do território são valorizados e desvalorizados, determinam mudanças de usos, é temerária.".

\footnotetext{
Assim como se fala de produtividade de uma máquina, de uma plantação, de uma empresa, podemos, também, falar de produtividade espacial ou produtividade geográfica, noção que se aplica a um lugar, mas em função de uma determinada atividade ou conjunto de atividades. Essa categoria se refere mais ao espaço produtivo, isto é, ao "trabalho" do espaço. Sem minimizar a importância das condições naturais, são as condições artificialmente criadas que sobressaem, enquanto expressão dos processos técnicos e dos suportes geográficos da informação. (SANTOS, 1996, p.166)
}

No estado de São Paulo, a relativa desconcentração industrial está associada à complexidade do seu território, historicamente dotado de condições de fixos e móveis que consolidaram o estabelecimento de circuitos espaciais da produção e 
círculos de cooperação na região metropolitana e que se expandiu para o interior, por sistemas de transportes, de importantes rodovias como a dos Bandeirantes, Anhanguera, Castelo Branco, Washington Luís, Dom Pedro, Dutra, Anchieta, Imigrantes, entre outras que conectam a metrópole com os munícipios do interior, litoral e outros estados. O emaranhado de redes de comunicação estabelecida por fibras ópticas interliga os circuitos espaciais da produção de maneira imaterial.

Nesse processo de integração global, novas paisagens industriais se revelam no território, em uma dinâmica interação com as antigas paisagens industriais, que não necessariamente deixam de existir, adquirindo novos usos e funções. Novas formas de produção, ocasionadas pelo amplo processo de reestruturação produtiva global são estabelecidas, tendo como exemplos os Condomínios Industriais, os Consórcios Modulares e de modelos híbridos com a Montagem Modular Sequenciada.

Cabe explicar que no caso dos Condomínios Industriais os fornecedores encontram-se localizados no mesmo terreno (site) que está instalada a fábrica montadora. No caso dos Consórcios Modulares, os fornecedores encontram-se localizados dentro da fábrica contratante. Existem, também, os modelos híbridos, denominados de Montagem Modular Sequenciada, que consiste na participação direta dos setores na linha de montagem, compartilhando o mesmo espaço e responsabilidades. Tais experiências demonstram que não existe um caminho único para a rede de fornecedores na indústria. As empresas buscam configurações eficientes, racionais e viáveis, ou seja, novos formatos para agilizar o processo produtivo e a reprodução do capital. (MENDES, 2014, p. 124).

Desta maneira, as principais regiões metropolitanas do estado de São Paulo - Campinas, Baixada Santista, Vale do Paraíba e litoral norte, Sorocaba e Ribeirão Preto e as aglomerações urbanas de Piracicaba, Jundiaí e Franca, formam uma rede urbana de cidades grandes, médias e pequenas polarizadas pela metrópole paulistana e instituídas nos circuitos espaciais da produção paulista, sendo territórios ativos nos círculos de cooperação. É nesse contexto que as pequenas cidades do interior paulista, integradas aos circuitos espaciais da produção e dadas às suas condições históricas, são inseridas no fluxo global da produção, tal como a instalação da unidade produtiva da Mercedes-Benz no pequeno município de Iracemápolis.

\section{INDÚSTRIA AUTOMOTIVA E MERCEDES-BENZ NO BRASIL}

A partir da década de 1950, o Brasil entra, de fato, no contexto de internacionalização da produção automotiva. No segundo mandato do Presidente Getúlio Vargas (1950-1954), a indústria automotiva brasileira, a partir de uma 
série de medidas governamentais, concedidas na apresentação do Plano Nacional de Estímulo à Produção de Automóveis, institucionalizou o que Latini (2007) chamou de "Certidão de nascimento" da indústria automobilística do Brasil

O fomento de subsídios, pautado na necessidade de nacionalizar a produção, da opção por um modelo de modais de transportes majoritariamente rodoviário, do crescimento do mercado consumidor brasileiro, estabeleceu condições de atração de multinacionais do setor automotivo para o país.

É no cenário de expansão das indústrias automotivas no Brasil que a indústria alemã Mercedes-Benz decidiu instalar sua primeira unidade produtiva no Brasil no ano de 1956, na cidade de São Bernardo do Campo, região metropolitana de São Paulo no ABCD paulista, para a produção de caminhões. No ano de 1979, a Mercedes-Benz implantou mais uma unidade produtiva no país, na cidade de Campinas, interior de São Paulo.

Até a década de 1980 a indústria automotiva no Brasil cresceu de maneira ininterrupta, balizada nas políticas de incentivos governamentais, mas, em decorrência da forte crise econômica que o Brasil enfrentou na década de 1980 como um cenário de inflação galopante, o poder de consumo entrou em declínio.

Nesse sentido, a década de 1990 foi de intensa reestruturação produtiva no ramo automotivo brasileiro, com um amplo processo de automação industrial e consolidação de práticas de produção flexíveis.

Entre 1992 e 1993 foi criada a Câmara Setorial Automotiva, com o objetivo de negociar e estancar a crise do ramo, constituída pelos principais agentes do circuito da produção automotiva, como o governo, indústria (automotiva e de autopeças), sindicatos e concessionárias.

Em 1993, o presidente Itamar Franco firma acordos com as montadoras para a produção dos chamados "carros populares", com o claro objetivo de estimular o aumento da venda de veículos, tendo em vista que estes carros possuíam uma série de subsídios.

Historicamente, a pressão do empresariado do ramo automotivo, capitaneados pela ANFAVEA- Associação Nacional dos Fabricantes de Veículos Automotores, sempre foi muito forte na busca de obtenção de subsídios, benefícios fiscais, financiamentos do BNDES - Banco Nacional de Desenvolvimento Econômico e Social, entre outras amenidades oferecidas pelo Estado brasileiro, com a participação também dos estados e municípios, que a partir de 1988, com a nova constituição, passaram a ter maior autonomia para oferecer incentivos para as indústrias, o que fomentou a guerra fiscal entre os estados. 
As deslocalizações de atividades industriais têm sido precedidas, não raro, por uma acirrada competição entre Estados e municípios pela instalação de novas fábricas e, mesmo, pela transferência das já existentes. A indústria do automóvel e das peças é emblemática de tal situação. Até recentemente, a política territorial das corporações automobilísticas buscava as benesses da localização metropolitana, mas, a partir da década de 1990, coloniza novas porções do território, revelando, mais uma vez, a historicidade dos fatores de localização. Tais recursos normativos se tornam ativos e, assim, criam vantagens comparativas para poucos agentes. (SILVEIRA, 2011, p. 06).

Em 1995, o presidente Fernando Henrique Cardoso substitui a Câmara Automotiva e institui o Regime Automotivo, estabelecendo mais uma série de subsídios como fomento da indústria automotiva no Brasil.

O Regime Automotivo, implantado a partir de 1995, impulsionou a indústria automotiva no Brasil. Até então, apenas as montadoras, que se instalaram no país entre as décadas de 1950-1970, produziam e dominavam o mercado automotivo brasileiro. Com o Regime Automotivo e suas benesses para o grande capital, as principais corporações automotivas promoveram investimentos estrangeiros diretos; tanto as indústrias já instaladas, como de outras corporações que ainda não tinham fábricas no país, aproveitando as condições dos atrativos do fordismo periférico.

Em 1999, a Mercedes-Benz inaugurou sua terceira unidade produtiva no país, descentralizando sua produção para o estado de Minas Gerais na cidade de Juiz de Fora, que além de caminhões, implementou, em sua linha de produção o carro Classe A, com características mais popular do que outros modelos luxuosos de automóveis da marca, na tentativa de expandir a sua marca no mercado latino americano, estratégia que se mostrou equivocada, diante da interrupção da produção do Classe A, em 2005.

$\mathrm{Na}$ década de 2000, fundamentalmente a partir de 2002, com a eleição do presidente Luís Inácio Lula da Silva foram criadas novas políticas de fomento para a indústria automotiva, o que possibilitou a vinda de novas corporações para produzir no país. Além disso, como forma de estímulo à venda de novos veículos, o governo Lula criou uma série de desonerações fiscais como, por exemplo, a isenção por determinados períodos do IPI - Imposto sobre Produtos Industrializados para veículos de 1.000 cilindradas, popularmente conhecidos como veículos de motores 1.0.

Em 2010, Dilma Rousseff assumiu a presidência do país e, no ano de 2011, anunciou o Programa de Incentivo à Inovação Tecnológica e Adensamento da Cadeia Produtiva de Veículos Automotores (INOVAR-AUTO), um programa específico para a indústria automotiva, que teve como objetivo fomentar 
o investimento baseado em inovações tecnológicas com metas para o investimento em Pesquisa e Desenvolvimento (P\&D), produção de veículos mais econômicos e seguros. As indústrias que atenderem as metas são beneficiadas como reduções do IPI em até 30\%.

Em 2016, a Mercedes instalou sua quarta unidade produtiva, localizada no município de Iracemápolis, interior de São Paulo, sendo essa a primeira fábrica exclusivamente para produção de automóveis. As três unidades produtivas da Mercedes-Benz, no Brasil, instaladas no século XX, passaram por intensos processos de reestruturação produtiva e a unidade produtiva de Iracemápolis, foi projetada dentro das novas características de produção global.

De acordo com o presidente da Mercedes-Benz no Brasil, o alemão Philipp Schiemer, um dos principais fatores que levaram a Mercedes-Benz a construir mais uma unidade no Brasil ocorreu pelo estabelecimento de regras e incentivos do programa INOVAR-AUTO. "O programa estabeleceu uma cota de importação de 4.800 veículos por ano, bem menos do que vendemos. Se não fizéssemos a fábrica, perderíamos competitividade - temos uma rede de concessionárias para manter aqui, e a conta não fecharia”. (BERTÃO, 2017)

O programa INOVAR-AUTO foi encerrado em 31 de dezembro de 2017 sendo substituído pelo programa ROTA-2030.

O novo regime automotivo Rota 2030, estimula as montadoras que atingirem como metas de eficiência energética em $11 \%$ até 2022, etiquetagem sobre os itens de segurança oferecidos pelo veículo, introdução de novos equipamentos obrigatórios de segurança até 2027 , veículos elétricos e híbridos receberão descontos entre $7 \%$ e $20 \%$ dos $25 \%$ cobrados de IPI.

Além das desonerações, de até 1,5 bilhão anual para as indústrias que investirem em P\&D, o Rota 2030 elimina as barreiras tributárias de $30 \%$ de IPI sobre a importação de veículos, que estabelecia uma cota de 4.800 veículos importados isentos. Com o novo regime, não existe mais diferenciação de tributação sobre a quantidade de veículos importados

O Regime Automotivo Rota 2030 tem duração de 15 anos e busca fomentar o investimento em Pesquisa \& Desenvolvimento na indústria automotiva brasileira, como contrapartida de desonerações fiscais. "Pelos cálculos do governo, a renúncia total de receita deverá ser da ordem de R \$2,113 bilhões para 2019 e de R\$ 1,646 bilhão para 2020. A medida não terá impacto em 2018" (STOCHERO, 2018).

Ao longo dos quase 70 anos das indústrias automotivas no Brasil, o Estado brasileiro não apoiou do desenvolvimento de uma indústria automotiva nacional 
forte e soberana, além de bilhões e bilhões em tributos não arrecadados em desonerações, atendendo as pressões do lobby promovido pelas grandes corporações multinacionais.

\section{O USO CORPORATIVO DO TERRITÓRIO EM PEQUENAS CIDADES}

Ao longo do século XX e XXI, diante das constantes transformações promovidas no interior do sistema capitalista, instituídas pelas novas dinâmicas e necessidade de fluidez do capital, como resultado da sua natureza da reprodução desigual, articulada e expandida, as pequenas cidades passam a desempenhar novas funções na divisão territorial do trabalho, integradas em circuitos espaciais da produção, promovidas pela intensa evolução tecnológica e de reestruturações produtivas globais. Selingardi-Sampaio (2009, p.30) aponta que "o tradicional padrão hierárquico se encontra em processos de (des) construção/reconfiguração, uma vez que pequenas cidades podem interagir com centros mundiais de primeira e segunda ordem, sem intermediações escalares".

No Brasil, existe um número significativo de pequenas cidades, de tal forma que a elevada ocorrência de pequenos centros deriva, "de um lado, de uma necessária economia de mercado, por mais incipiente que seja geradora de trocas fundamentadas em uma mínima divisão territorial do trabalho." (CORRÊA, 1999, p.3).

Conceituar pequenas cidades não é uma tarefa fácil, tendo em vista a possibilidade de uma análise reducionista quantitativa. Nesse sentido, é preciso considerar que as pequenas cidades possuem particularidades e heterogeneidades. Em tempos de integração global, outro cuidado necessário está relacionado à hierarquização por critérios políticos administrativos; como regiões metropolitana, administrativas ou aglomerações urbanas.

As pequenas cidades não devem ser classificadas apenas pelo critério do tamanho populacional. Ao analisar as transformações e dinamismo das pequenas cidades, deve-se levar em consideração as centralidades e a importância que as mesmas desempenham na rede urbana, para não acarretar em um risco metodológico de um mero reducionismo analítico. Todavia, cabe ressaltar que o número de habitantes também pode ser considerado como um dos diversos elementos de análises para compreender as transformações espaciais em pequenas cidades e pode ser adotado como um ponto de partida para a compreensão da produção do espaço urbano em pequenas cidades. Nesse sentido, IBGE e IPEA - Instituto de Pesquisa Econômicas Aplicada - definem, a partir de critérios quantitativos, o número de 50.000 mil habitantes para definição de pequenas cidades, para fins de análises estatísticas. 
Considerando a heterogeneidade das cidades brasileiras e a participação na rede urbana, a classificação de pequenas cidades torna-se complexa. De modo geral, a classificação por número de habitantes de pequenas cidades, com população inferior a 50 mil habitantes reflete pouca expressão na rede urbana e possuem, geralmente, estreita relação com o campo. Tais cidades, por não possuírem infraestruturas e outros serviços são, portanto, dependentes de centros urbanos de maior porte.

De qualquer modo, por mais que tais características predominem na análise sobre pequenas cidades, é possível constatar que determinadas cidades inseridas em circuitos espaciais da produção têm atraído grandes corporações multinacionais, oferecendo vantagens comparativas para a instalação de grandes indústrias, promovendo assim novos arranjos territoriais. As pequenas cidades que antes tinham funções apenas político-administrativas, adotam novas funções, como cidades-dormitórios, reservas de mão de obra e cidades industriais.

As pequenas cidades, a partir de suas funções nas divisões territoriais do trabalho, estabelecem conexões com os mercados internacionais mediante à divisão territorial do trabalho e o processo de globalização, interligadas pelos circuitos espaciais de produção e círculos de cooperação, atraindo e dinamizando o processo produtivo, levando sempre em consideração as suas particularidades e heterogeneidades.

Hoy existe la posibilidad de estar ligado con redes económicas internacionales y
conocer el ritmo de los mercados mundiales. También la de conectarse desde ciuda-
des pequeñas y actuar en red con otras situadas en diferentes lugares del mundo, a
partir de una solidaridad de intereses. Lo cual significa que las redes de cooperaci-
ón, que son indispensables con el entorno y con las ciudades próximas, también son
posibles con otras lejanas, para objetivos comunes, buscando sinergias, solidarida-
des, saber compartido, mercados, publicidad común, intercambio de conocimientos.
(CAPEL, 2009, p. 22)

No que tange às pequenas cidades e a sua inserção no contexto global, cabe reforçar o papel contraditório e de subordinação das mesmas em relação à lógica reprodutora do capital, que se apropria e faz uso desses territórios para atender seus interesses. Conforme Endlich (2009):

[...] os papéis econômicos das pequenas cidades não dizem respeito estritamente aos interesses de seus habitantes. Ao contrário, são espaços capturados, em vários aspectos, por interesses que lhes são alheios. Compreender as pequenas cidades apenas por esse ângulo mostra uma dimensão em que tais espaços não estão para as sociedades locais, isto é, para os seus moradores. (ENDLICH, 2009, p. 286) 
As pequenas cidades, inseridas em circuitos espaciais da produção, possuem relações contraditórias, simultâneas e mescladas, diante dos tempos lentos de relativa tranquilidade, pela proximidade dos lugares e pela facilidade de circulação a pé ou de outros meios de transporte, como carros.

\footnotetext{
Nas pequenas cidades, é possível percorrer alguns trajetos cotidianos a pé, e mais, caminhar devagar, pois não há uma multidão impondo um ritmo forçado. Então a tranquilidade está relacionada [...] a facilidade de locomoção, pela facilidade que permite o pedestrianismo ou pelo trânsito descongestionado para os que utilizam veículos automotores. (ENDLICH, 2009, p. 291).
}

Por outro lado, o tempo imposto pelo ritmo de trabalho da população trabalhadora, impede o desfrutar desse tempo lento, tendo em vista a jornada de trabalho imposta pelas grandes corporações.

Para a multidão de trabalhadores que dependem do cumprimento de metas diárias, a possibilidade de se arrefecer o ritmo não se apresenta como algo que possa resultar de uma decisão individual. São pessoas que não podem apropriar-se de seu tempo, pois ela é a medida da quantidade do trabalho vendido, única via para a sua reprodução. (ENDLICH, 2009, p. 293).

É nesse contexto, que Iracemápolis, pequena cidade do estado de São Paulo, tem participado ativamente dos circuitos espaciais da produção paulista, inserida na rede global de produção, tendo como principal agente de inserção a unidade produtiva da Mercedes-Benz, projetada em 2013 e inaugurada na cidade no ano de 2016.

\section{IRACEMÁPOLIS EA MERCEDES-BENZ}

O município de Iracemápolis dista $157 \mathrm{~km}$ da cidade de São Paulo, sendo limítrofe de munícipios como Limeira $18,5 \mathrm{~km}$ a leste, Rio Claro $26 \mathrm{~km}$ a norte, Santa Barbara do Oeste $27 \mathrm{~km}$ a oeste e Piracicaba $29 \mathrm{~km}$ a Sul.

Assim sendo, Iracemápolis está dentro da referida "cidade-região" proposta por Lencioni (2004) e do "Multicomplexo territorial industrial paulista" conceituado por Selingardi-Sampaio (2009), servida por rodovias importantes como a dos Bandeirantes (SP-348) e Anhanguera (SP-330). Tais rodovias possibilitam a interligação com Campinas e São Paulo, centros decisórios e receptores de mercadorias. Iracemápolis tem uma posição estratégica nos circuitos espaciais da produção paulista, por sua proximidade com os principais centros urbanos do estado.

As 3 rodovias que cortam o munícipio são as seguintes: Rodovia Luís Ometto (SP-306), Rodovia Dr. João Mendes da Silva Júnior (SP-151) e pela Rodovia Dep. Laercio Corte (SP-147). 
No que se refere ao seu desenvolvimento econômico, Iracemápolis sempre se caracterizou pela atividade sucroalcooleira, tendo como principal referência à usina Iracema, grande produtora de açúcar e álcool.

A partir da década de 1990 a cidade de Iracemápolis ganhou dinamismo econômico, mesmo com o domínio da indústria sucroalcooleira, pequenas e médias indústrias passam a se instalar no município.

As transformações ocorridas ao longo do século XX e início do XXI devem-se à posição estratégica do munícipio, dotadas por uma rede de rodovias que interliga a cidade a centros importantes como Piracicaba e Rio Claro, que teve o acesso facilitado na década de 1990, pela duplicação da Rodovia Fausto Santo Mauro (SP-127) e, ainda, pela duplicação, na mesma década, da rodovia Dep. Laercio Corte - (SP-147) que liga Piracicaba a Limeira.

Na década de 2000, o munícipio foi contemplado com o prolongamento da Rodovia dos Bandeirantes (SP 348) até a cidade de Limeira, aproximando o traçado da rodovia a apenas $5 \mathrm{~km}$ do município, facilitando o acesso a cidades como Campinas, São Paulo e ao porto de Santos.

Mapa 1 - Principais rodovias de acesso e escoamento de Iracemápolis

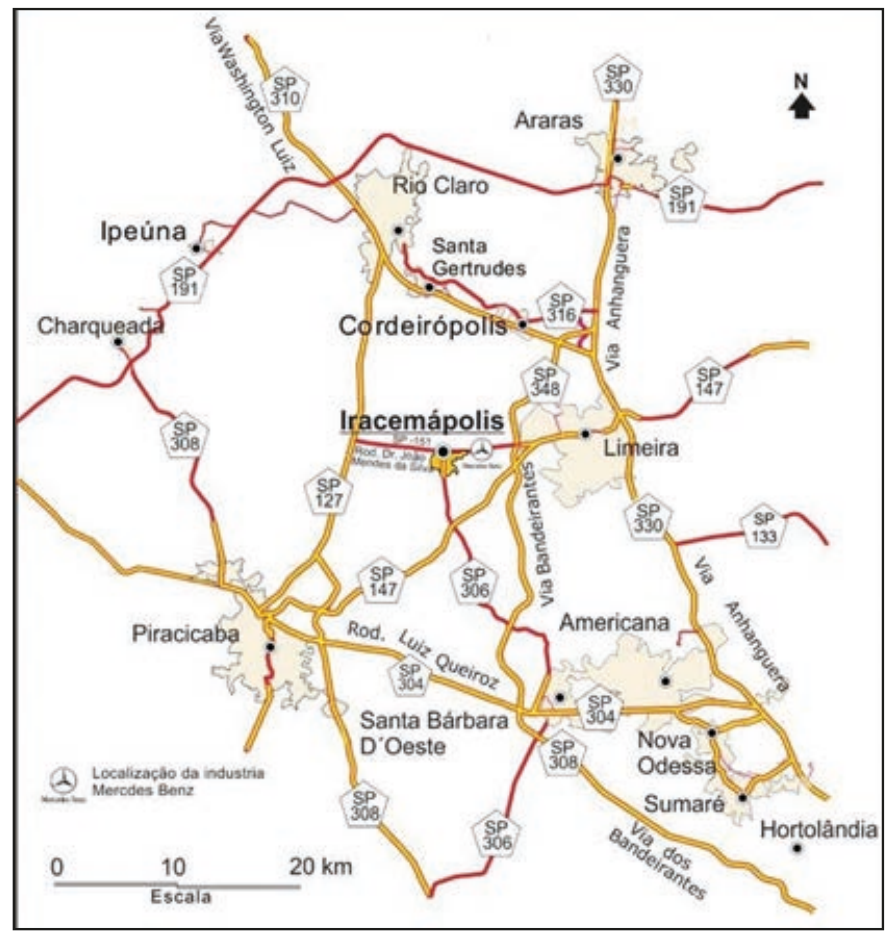

Fonte: Mapa Rodoviário do Estado de São Paulo - DER - 2017 - Des. HENRIQUE, Gilberto D.- Org. LOVADINI, Mauricio, 2017. 
De acordo com os dados do Instituto Brasileiro de Geografia e Estatística - IBGE (2018), o município possui uma área territorial de 115, $118 \mathrm{Km}^{2}$, com uma população de 20.029 pessoas, de acordo com o último censo de 2010, e uma densidade demográfica de 173,9 habitantes por $\mathrm{Km}^{2}$. A população estimada para 2018 é de 23.846 habitantes.

Na década de 2010, Iracemápolis foi escolhida para abrigar as instalações de uma unidade produtiva de automóveis premium da Mercedes-Benz, fato que notabilizou o município no cenário produtivo nacional.

Para compreender o processo de escolha e instalação da unidade produtiva da Mercedes-Benz em Iracemápolis, o ex-prefeito Sr. Valmir Gonçalves de Almeida (PSD), prefeito que intermediou a vinda da montadora para Iracemápolis foi entrevistado, atendendo, gentilmente, em sua residência.

Ao ser indagado sobre o interesse da Mercedes-Benz para a instalação de uma unidade produtiva na cidade de Iracemápolis, o ex-prefeito revelou que associados a outros fatores, os incentivos oferecidos pelo município foram determinantes para que a montadora escolhesse Iracemápolis.

O Programa de Incentivos ao Desenvolvimento Econômico Sustentável, Geração de Emprego e Renda - denominado 'PRODESENVOLVE Iracemápolis', que entrou em vigor em 2013, oferece uma série de desonerações para empresas que se instalarem no município, como apontam os quadros 1 e 2 . 
Quadro 1 - Principais incentivos - PRODESENVOLVE Iracemápolis

Art. $3^{\circ} \mathrm{O}$ programa instituído por esta lei contempla o reembolso dos investimentos financeiros despendidos com aquisição e locação de terrenos, construção, ampliação e adaptação de imóveis; serviços de terraplanagem, obras de infraestrutura e benfeitorias, desde que realizados para o desenvolvimento direto da atividade econômica da empresa e aprovados pela Câmara Técnica de Desenvolvimento Sustentável - CTDS. (Redação dada pela Lei Municipal no 2.050, de 2013).

Art. $4^{\circ}$ Os reembolsos, isenções e restituições autorizados nesta Lei serão realizados até o limite dos investimentos financeiros despendidos, nos termos do art. $3^{\circ}$, ou no prazo máximo de 20 (vinte) anos, o que ocorrer primeiro, e serão quantificados no ato da aprovação pela CTDS em Unidades Fiscais do Estado de São Paulo - UFESP, ou outro índice que venha a substituí-la, gerando créditos passíveis de reembolso à empresa empreendedora na seguinte forma: (Redação dada pela Lei Municipal n 2.063, de 2013)

IV - Restituição do montante correspondente a $50 \%$ (cinquenta por cento) da quota parte do valor adicionado transferido mensalmente ao Município em decorrência do incremento do valor adicionado gerado pela atividade econômica da empresa beneficiada na formação do índice do ICMS - Imposto sobre Circulação de Mercadorias e Prestação de Serviços, nos termos desta Lei calculado de conformidade com o previsto nas alíneas abaixo: (Redação dada pela Lei Municipal no 2.290, de 2016).

V - Restituição do montante correspondente a 50\% (cinquenta por cento) do valor do ISSQN - Imposto sobre Serviços de Qualquer Natureza, gerado mensalmente pela atividade econômica exercida pela beneficiária, nos termos desta lei. (Redação dada pela Lei Municipal ${ }^{\circ}$ 2.063, de 2013).

$\S 2^{\circ}$ A restituição da quota-parte do valor adicionado de que trata o inciso IV, poderá ser ampliada nos percentuais e condições a seguir dispostas, podendo alcançar até $60 \%$ (sessenta por cento): (Redação dada pela Lei Municipal n 2.063, de 2013)

a) 4\% (quatro por cento), no caso de a beneficiária possuir a certidão ISO 9000 - Gestão de Qualidade ou equivalente; (Redação dada pela Lei Municipal nº 2.063, de 2013)

b) $3 \%$ (três por cento), no caso de a beneficiária possuir a certidão ISO 14000 - Gestão Ambiental ou equivalente; (Redação dada pela Lei Municipal nº 2.063, de 2013)

c) 3\% (três por cento); no caso da beneficiária possuir a certidão SA 8000 - Responsabilidade Social ou equivalente. (Redação dada pela Lei Municipal nº 2.063, de 2013).

Fonte: Câmara Municipal de Iracemápolis (Lei municipal n² 2.013/2013). : Org. LOVADINI. Mauricio, 2018.

Para o ex-prefeito, os artigos $3^{\circ}$ e $4^{\circ}$ e o inciso IV e $\mathrm{V} \S 2^{\circ}$ alíneas a), b) e c) foram determinantes para que a MB escolhesse Iracemápolis, porém, além desse dispositivo, a lei contempla uma série de outros benefícios que estimularam a vinda da montadora para o munícipio, tais como os reembolsos na aquisição e locação de terrenos, construção, ampliação e adaptação de imóveis no período da instalação como aponta o artigo $3^{\circ}$ da lei. 
As séries de isenções de impostos municipais estão especificadas nos incisos I, II, III do artigo $4^{\circ}$ da legislação.

Quadro 2 - Isenção de impostos municipais.

I - Isenção do ISSQN - Imposto sobre Serviços de Qualquer Natureza, incidente sobre serviços de construção civil, engenharia, arquitetura e montagem industrial, prestados na fase de implantação ou ampliação do empreendimento; (Redação dada pela Lei Municipal n ${ }^{\circ}$ 2.063, de 2013)

II -Isenção do IPTU - Imposto Predial e Territorial Urbano, incidente sobre o imóvel ocupado, ainda que temporariamente, pelo empreendimento na fase de sua implantação, e sobre o imóvel onde será definitivamente instalado o empreendimento; (Redação dada pela Lei Municipal $n^{\circ} 2.063$, de 2013)

III - Isenção do ITBI - Imposto de Transmissão de Bens Imóveis incidente sobre a aquisição do imóvel onde será definitivamente instalado o empreendimento; (Redação dada pela Lei Municipal $n^{\circ} 2.063$, de 2013)

Fonte: Câmara Municipal de Iracemápolis (Lei municipal $n^{\circ}$ 2.013/2013).: Org. LOVADINI, Mauricio, 2018.

Além dos incentivos fiscais, Iracemápolis está inserida estrategicamente em uma região de desenvolvimento industrial.

O município de Iracemápolis está localizado na Região Administrativa de Campinas. Composta por 90 munícipio a R.A de Campinas é dotada de importantes redes de circulação de pessoas, mercadorias e capitais.

A instalação da nova unidade produtiva da Mercedes-Benz em Iracemápolis está relacionada ao fato da decisão da montadora em instalar uma nova unidade no Brasil, por conta das cotas de importações do regime Inovar-Auto.

Após a decisão da montadora para instalação de uma nova unidade produtiva no Brasil, a escolha da cidade passou por intensas disputas entre os estados. Segundo o ex-prefeito Valmir Gonçalves de Almeida, seis estados concorreram: São Paulo, Minas Gerais, Paraná, Rio de Janeiro, Santa Catarina e Rio Grande do Sul, contemplando uma infinidade de cidades pleiteando a instalação da unidade produtiva da $\mathrm{MB}$.

Diante do estudo de todo aspecto técnico para a viabilidade da escolha das cidades pela montadora, três deles foram escolhidos para a disputa final, Iracemápolis e Salto no interior de São Paulo, além de Joinville no norte de Santa Catarina.

O investimento inicial de R\$500 milhões chegou aos 600 milhões em 2016, ano de inauguração da indústria na cidade de Iracemápolis. A escolha do local para a instalação da unidade produtiva passou por uma análise estratégica da 
corporação, levando em conta fatores locacionais, vantagens comparativas e incentivos fiscais.

\section{CONSIDERAÇÕES FINAIS}

Iracemápolis tem passado por novas transformações, com o surgimento de condomínios residenciais fechados; projetos de condomínio empresarial; o surgimento de mais uma torre de prédio de grande porte; dinamização das redes de serviços comerciais, com a chegada de franquias, tais como: a rede de fastfood Subway, da rede de farmácias Drogal de Piracicaba, da rede de cosmético $O$ Boticário, da rede de chocolates Cacau Show, da rede de Óticas Carol, entre outras, que têm impulsionado o comércio na cidade. O munícipio conta, atualmente, com 5 agências bancárias (Banco do Brasil, Caixa Econômica Federal, Itaú, Bradesco e Sicredi).

A cidade também avançou no que diz respeito a legislações de planejamento urbano, aprovadas em 2016, como o primeiro plano diretor, além do plano municipal de saneamento, melhorando o armazenamento de água e tratamento de esgoto.

Diante desse cenário dinâmico, de transformações ocorridas ao longo dos anos, Iracemápolis passa a desempenhar uma nova função na divisão territorial do trabalho e da produção em várias escalas espaciais, tendo como marco dessa inserção a implantação da indústria automotiva alemã Mercedes-Benz.

A vinda da Mercedes-Benz para Iracemápolis consolidou o SENAI (Serviço Nacional de Aprendizagem Industrial) que, atualmente, tem estrutura para atender à demanda regional, sendo que uma das exigências da Mercedes-Benz era ter uma escola de formação técnica profissional de ponta.

Para a Mercedes-Benz, foi criado um espaço industrial exclusivo para a sua produção. Em frente ao distrito industrial da Mercedes-Benz, existe uma grande área estabelecida pela legislação municipal, como distrito industrial destinado às grandes indústrias, projetado primeiramente para a instalação de indústrias de autopeças para atender as demandas da Mercedes-Benz, porém, essas indústrias ainda não se instalaram na cidade. Nesse distrito é previsto a construção de um hotel e de um centro de convenções. O principal argumento para a não concretização dos projetos é a crise político-econômica estabelecida no país, atualmente.

Entre os fatores locacionais, Iracemápolis conta com uma posição geográfica estratégica, próxima dos principais centros de distribuição e consumo. Localizada a menos de $30 \mathrm{~km}$ de centros regionais como Piracicaba e Limeira, 
cerca de $90 \mathrm{~km}$ da metrópole de Campinas e uma distância de $170 \mathrm{~km}$ de uma das principais metrópoles do mundo, a cidade global de São Paulo.

Por essa proximidade geográfica, Iracemápolis está inserida nos principais circuitos de produção e círculos de cooperação, próxima de importantes vias de interligação do estado de São Paulo, como a rodovia dos Bandeirantes e Anhanguera, além da proximidade com o Porto de Santos, o maior da América Latina, a menos de $240 \mathrm{~km}$ de Iracemápolis.

A instalação da unidade produtiva da MB em Iracemápolis estabeleceu novas relações com outras escalas geográficas, interligando a pequena cidade com centros decisórios como São Paulo e com a sede da corporação na Alemanha.

Por ser uma pequena cidade, sem tradição industrial e com características voltadas para atividades agrícolas, Iracemápolis possui grandes áreas em seu território que podem ganhar novas funções, como é o caso da transformação da área até então utilizada no cultivo de cana-de-açúcar transformada em área de produção industrial com a instalação da Mercedes-Benz.

Não obstante a cidade estar inserida em uma região estratégica, dotada de redes produção e circulação, a estratégia utilizada pela MB para a instalação de uma nova unidade no Brasil, se assemelha aos greenfields dos Estados Unidos, áreas com pouca ou sem nenhuma tradição industrial com características singulares, comparadas a áreas industriais densas e consolidadas.

As áreas de greenfields têm como atrativos médias salariais mais baixas comparadas com regiões industrializadas, interesse de autoridades locais/regionais em atrair investimentos estrangeiro direto, gerando empregos e maior arrecadação de impostos, relativas hostilidade ao sindicalismo, incentivos fiscais, entre outros benefícios de atração e interesse de grandes corporações para o uso do território. Tal estratégia foi utilizada pela MB na década de 1990, com a instalação de uma unidade produtiva em uma área de greenfield nos EUA, na cidade de Tuscaloosa, no estado do Alabama que, nos dias atuais, conta com 90 mil habitantes.

Os agentes produtores do espaço, especificamente os agentes públicos governamentais tiveram um papel fundamental para que a $\mathrm{MB}$ se instalasse em Iracemápolis. A atuação dos agentes públicos (federal, estadual e municipal) foi de suma importância nesse processo e os fatores relacionais entre eles possibilitaram a escolha da MB por Iracemápolis.

A atuação mais incisiva foi do poder público municipal, diante do fato que para o governo federal o importante era que a MB trouxesse mais uma unidade 
produtiva para o país, independente do qual estado e cidade a corporação escolhesse, para isso o regime automotivo Inovar-Auto foi um fator determinante.

Da mesma maneira, o governo do estado de São Paulo tinha o interesse de que a MB se instalasse no estado, independente da cidade. Para tanto criou condições de atração para que a MB escolhesse o estado de São Paulo, como o programa de incentivos fiscais Pró-Veículo e de completa consultoria para a MB, através da agência de fomento Investe São Paulo, responsável pela intermediação entre a grande corporação automotiva e o poder público municipal de Iracemápolis.

$\mathrm{O}$ poder público municipal teve papel determinante para que a cidade fosse escolhida para a instalação da unidade produtiva da MB. A participação do processo seletivo, intermediado pelo governo do estado, só foi possível pela criação de uma legislação municipal que oferecesse uma gama de benefícios de atração de indústrias para a cidade. O programa de incentivos Prodesenvolve Iracemápolis foi fundamental para que a cidade entrasse no cenário da divisão internacional e territorial do trabalho a partir da produção industrial. Tais benefícios fiscais estabelecidos pelo programa foram tão atrativos, que fizeram a MB escolher a cidade, superando outras dificuldades como a compra da área, mesmo que subsidiada e a relação hostil e combativa do ponto de vista da luta dos direito dos trabalhadores do sindicato em relação à corporação.

Os esforços do poder público municipal para que Iracemápolis fosse escolhida para instalação de uma unidade produtiva da MB demonstra a importância dos agentes de produção do espaço, nesse caso o Estado, como instrumento de uso das grandes corporações para sua maior lucratividade, utilizando-se de todo tipo de benefícios e do uso dos recursos naturais e humanos para atender à incessante reprodução do capital.

O principal argumento de contrapartida do poder público municipal em meio a tantos benefícios se justifica, muitas vezes, na geração de emprego, arrecadação de impostos e desenvolvimento socioeconômico do munícipio.

A possibilidade de instalação da uma grande indústria em uma cidade gera expectativa na população em relação à empregabilidade, principalmente em uma pequena cidade, porém, essa expectativa muitas vezes não se realiza.

Do ponto de vista da geração de emprego, o processo de automação industrial, robótica e todo aparato das tecnologias de ponta da indústria 4.0 tem reduzido significativamente o número de empregos nas indústrias. $\mathrm{Na}$ indústria automotiva, o número de trabalhadores empregados é menor comparado à geração de empregos na década de 1970, quando as indústrias adotavam o modelo de produção fordista. 
O discurso da geração de empregos em massa não se sustenta, Silveira (2011) aponta que "automatizados, os sistemas técnicos das empresas não produzem um impacto significativo na equação do emprego local”.

A arrecadação de impostos pode aumentar. De forma bruta a arrecadação aumenta, mas com as contrapartidas dos incentivos fiscais, o aumento da arrecadação é diluído nas renúncias fiscais, com o estorno de parte dos impostos previstos na legislação de volta para a corporação.

As grandes corporações usam e abusam do território, se aproveitam dos fatores locacionais e dos interesses e ações dos agentes do Estado para se instalarem onde melhor convém, sem necessariamente criar vínculos com lugar, usando o território como um enclave produtivo, tornando-o dependente do processo produtivo. Desta maneira, muitas vezes o poder público e a população dependentes do emprego se transformam em "reféns" das grandes indústrias, cedendo às chantagens quando os interesses econômicos da mesma não são atendidos, tal como a ameaça sobre o fechamento da unidade produtiva da $\mathrm{MB}$ em Iracemápolis caso algumas das demandas da montadora não fossem atendidas.

Dialeticamente, as contradições se materializam no território e ganham destaques nas ações e discursos. Nesse sentido, diante do uso do território pelas grandes indústrias, existem os saltos qualitativos de desenvolvimento abarcados pela instalação de uma unidade produtiva industrial de grande porte em uma pequena cidade.

Os fatores agentes e processos, utilizados e realizados como estratégias do capital para atender a sua reprodução diante de novas dinâmicas locacionais, se renovam de acordo as constantes necessidades de acumulação de riquezas a partir do uso do território.

Tais fatores, agentes e processos analisados na pequena cidade Iracemápolis na atração de uma grande indústria constituem, contemporaneamente, uma nova lógica, um novo momento na dinâmica locacional das indústrias, cujos efeitos negativos existentes nas grandes cidades e nas cidades médias, guardadas as devidas proporções, poderão, ainda, serem evitados.

\section{REFERÊNCIAS}

BERTÃO, Naiara. R\$ 600 milhões para nada? Mercedes pode fechar fábrica em SP. 2017. Disponível em: <https://exame.abril.com.br/revista-exame/r-600-milhoes-para-nada-mercedes-pode-fechar-fabrica-em-sp/>. Acesso em: 16 dez. 2017. 
CAPEL, H. Las pequenas ciudades em la urbanización generalizadas y ante la crisis global. Investigaciones Geográficas, Boletin del Instituto de Geografía, UNAM, v.70, p.7-32, 2009.

CORREAA, R. L. Globalização e reestruturação da rede urbana: uma nota sobre as pequenas cidades. Território, Rio de Janeiro, v. 4, n. 6, p. 43-52, 1999.

DICKEN, P. Mudança Global: as novas fronteiras da economia mundial - 5 . ed. - Porto Alegre: Bookman,2010.

ENDLICH, A.M. Pensando os papéis e significados das pequenas cidades. São Paulo: Ed. UNESP, 2009.

HARVEY, D. 17 Contradições e o fim do capitalismo. - $1^{\circ}$ ed. São Paulo: Boitempo, 2016.

IRACEMÁPOLIS. CÂMARA MUNICIPAL. Lei Municipal No 2.013. Dispõe sobre a criação do Programa de Incentivos ao Desenvolvimento Econômico Sustentável, Geração de Emprego e Renda - denominado "PRODESENVOLVE Iracemápolis" e dá outras providências. 2013. Disponível em: <http://consulta. siscam.com.br/camarairacemapolis/arquivo?Id=3790>. Acesso em: 31 jul. 2018.

LATINI, Sydney A.. A implantação da indústria automobilística no Brasil: Da substituição de importação ativa a globalização passiva. São Paulo: Alaúde, 2007.

LENCIONI, S. Novos rumos e tendências da urbanização e a industrialização no Estado de São Paulo. In: LIMONAD, E. et al. (Org.). Brasil século XXI: por uma nova regionalização? Agentes, processos e escalas. São Paulo: Max Limonad, 2004.

MENDES, A. A. Reestruturações Locais como Efeitos da Globalização Econômica: Uma Análise da Estrutura Produtiva Mutante do Pólo Têxtil de Americana - SP. Tese de Doutorado, Rio Claro, 1997. 
MENDES, A. A. Condomínios industriais e empresarias no Brasil. A Indústria automobilística e os novos espaços produtivos em Campinas (SP). Finesterra: Revista Portuguesa de Geografia, Lisboa, v. XLIX n. 97, p.119-134, 2014.

SANTOS. M. A Natureza do Espaço: Técnica e Tempo, Razão e Emoção - 4. ed. 2. reimpr. - São Paulo: Editora da Universidade de São Paulo, 2006. - (Coleção Milton Santos; 1)

SANTOS, M.; SILVEIRA, M. L. O Brasil: território e sociedade no início do século XXI. Rio de Janeiro: Record, 2004.

SELINGARDI-SAMPAIO, S. Indústria e território em São Paulo: a estruturação do Multicomplexo Territorial Industrial Paulista: 1950-2005. Campinas: Editora Alínea, 2009).

SILVEIRA, Maria Laura. TERRITÓRIO USADO: DINÂMICAS DE ESPECIALIZAÇÃO, DINÂMICAS DE DIVERSIDADE. Ciência Geográfica, Bauru, v. 15, n. 15, p.04-12, dez. 2011. Anual.

STOCHERO, Tahiane. Temer assina decreto que regulamenta novo programa de incentivos ao setor automotivo Rota 2030. 2018. Disponível em: $<$ https://g1.globo.com/sp/sao-paulo/noticia/2018/11/08/temer-sanciona-mp-que-cria-programa-de-incentivos-ao-setor-automotivo-rota-2030.ghtml>. Acesso em: 16 nov. 2018. 
